OSF Preprint

DOI: 10.31219/osf.io/9afp3

\title{
SARS-CoV-2 whole-genome classification analysis, protein homology modelling and elucidation of associated protein functions
}

\author{
Deepanshu Sharma (iD), Anamika Saini, Desh Deepak Singh \\ Amity Institute of Biotechnology, \\ Amity University Rajasthan, Jaipur, India
}

\section{ABSTRACT}

The most recent whole-genome sequence of SARS-CoV-2 was published on NCBI on $13^{\text {th }}$ March 2020, with accession no. NC_045512. The protein products, genetic features, sequence length, NCBI reference sequence, protein structures (published/ homology modelling) and functions are discussed and analysed in this paper. Multiple sequence alignment is performed and Phylogenic tree is prepared for the 4 closely related coronavirus species. This study provides the whole genome analysis with protein homology structures and elucidates functions of structurally similar proteins for further exploration and contributes to the search for antiSARS-CoV-2 drugs. The application of this data in new vaccine development techniques such as Rapid-Response Platform and a possibility of a recombinant SARS-CoV-2 are discussed in this paper.

Keywords: SARS-CoV-2; COVID-19; SARS-CoV; Protein structures; Protein functions; Homology modelling; BLAST; Whole-genome sequence; Rapid-Response Platform vaccines; Recombinant SARS-CoV-2

\section{INTRODUCTION}

The zoonotic virus of coronavirus (CoV) family, later named as Severe acute respiratory syndrome coronavirus 2 (SARS-CoV-2) was first reported in Wuhan, Hubei province in China in 31 December $2019^{1}$. On January 7, 2020 scientist identified it as coronavirus, same as which was emerged in China in 2002 and MERS which infected people in 2012. The next step was to understanding the sequence of the genome to find out the unique order of nucleotides. The COVID-19 genome is approximately $\sim 30 \mathrm{kbp}$, which is the largest group on the RNA virus genome. On January 13, 2020 scientist from Shanghai, China, sequenced the whole genome of SARS-CoV-2 by samples collected from the patients diagnosed with COVID-19. Compared with the SARS virus studied in November 2002 and MERS virus in April 2003, after this analysis scientist had declared it as new coronavirus. Furthermore, scientist of Shanghai, China has sequenced more than 24 samples with COID-19 to confirm the new virus 


\section{OSF Preprint \\ DOI: 10.31219/osf.io/9afp3}

genome. As the SARS-CoV-2 was sequenced, scientist around the world copies the viral gene for further study. This would help in drug and vaccine development against COVID-19.

The disease caused by this virus is named as COVID-19 and it is categorized as a pandemic by WHO on $15^{\text {th }}$ March 2020 (19:14 GMT), 167757 cases, 6456 deaths of COVID-19 were recorded by more than 150 counties, $50.35 \%$ (80849) cases are reported from China and $49.65 \%$ (79714) cases are reported by the rest of the world. Currently, COVID -19 is quickly transmitting throughout the world and the number of countries affecting in several areas, therefore, immediate preventive measure needs to be applied. Previous reviews on the COIVD19 were based on information from the specific problem. There is no vaccine specifically available for COVID-19.

The Coalition for Epidemic Preparedness Innovations (CEPI) is a global alliance financing and coordinating the development of vaccines against emerging infectious diseases (https://cepi.net/). CEPI is providing funding support for vaccine development process. The objective is to advance development of vaccine technology platforms that enable a rapid response to immunize at-risk populations against emerging infectious diseases.

Biotechnology companies such as Twist Bioscience, a San Francisco, California based company, manufacture customized DNA for clients. Such technology is very useful is new type of vaccine development method known as Rapid-Response vaccines.

Understating the genomic composition of this virus is the primary step to reveal the virus-host interaction mechanism and disease propagation which will be helpful to develop an effective treatment against SARS-CoV-2.

Many SARS-CoV-2 sequences are currently available in GenBank and the Sequence Read Archive (SRA). The database is continuously updated when any new sequence is reported.

\section{METHODS AND MATERIALS}

\section{Multiple sequence alignment}

The whole genome of SARS-CoV-2 with accession no. NC_045512.2 and SARS-CoV with accession no. NC_004718 was downloaded from the NCBI nucleotide database. The individual protein sequences were aligned for both the datasets using BLASTp to search for homology viral genomes and structural similarity parameter. Which is performed by using The SmithWaterman algorithm is used to calculate the local alignment of two whole-genome sequences 
OSF Preprint

DOI: 10.31219/osf.io/9afp3

63 from EMBOSS online tool as shown below -

64 (https://www.ebi.ac.uk/Tools/psa/emboss_water/).

65

66

67

\# Aligned_sequence: 2

\# 1: SARS-CoV-2 (NC_045512.2)

68

\# 2: SARS-CoV (NC_004718)

\# Matrix: EDNAFULL

\# Gap penalty: 10.0

\# Extend penalty: 0.5

\#

\# Length: 21620

\# Identity: $17251 / 21620$ (79.8\%)

\# Similarity: 17251/21620 (79.8\%)

\# Gaps: $\quad$ 729/21620 ( 3.4\%)

\# Score: $\quad 68746.5$

Alignment results showing Length, Identity, Similarity, Gaps

DNAfull matrix was used with Gap penalty 10 and Extended penalty 0.5 . The two genome shows a $79.8 \%$ similarity as well as identity.

77 Whole-genome sequencing of SARS-CoV-2 has uncovered varied dimensions for research and brought us one more step closer to understand the epidemiology of COVID-19. The actual source of viral outburst is still ambiguous, but the novel virus which was collected in Yunnan province, China has $96.2 \%$ similarity to a bat SARS-related coronavirus (SARSr-CoV;

81 RaTG13), 79\% similarity to SARS-Cov and 50\% similarity to MERS-CoV ${ }^{2}$, as previously reported.

83 Despite lesser genomic similarity, SARS-CoV-2 and SARS-CoV spike proteins share a 76.5\% 84 identity a high degree of homology 3,4 .

\section{2. Phylogenic Tree}

86 MEGA software with version 7.0.26 is used to perform alignment and build phylogenic tree

87 for the genome sequences of SARS-Cov-2 (MN908947), SARS-CoV (NC_004718), SARS88 CoV BJ01 (AY278488) and MERS-CoV (NC_019843). 
89 The evolutionary history was inferred using the Neighbor-Joining method. The optimal tree 90 with the sum of branch length $=1.62357032$ is shown in this analysis. The analysis involved 4 91 nucleotide sequences.

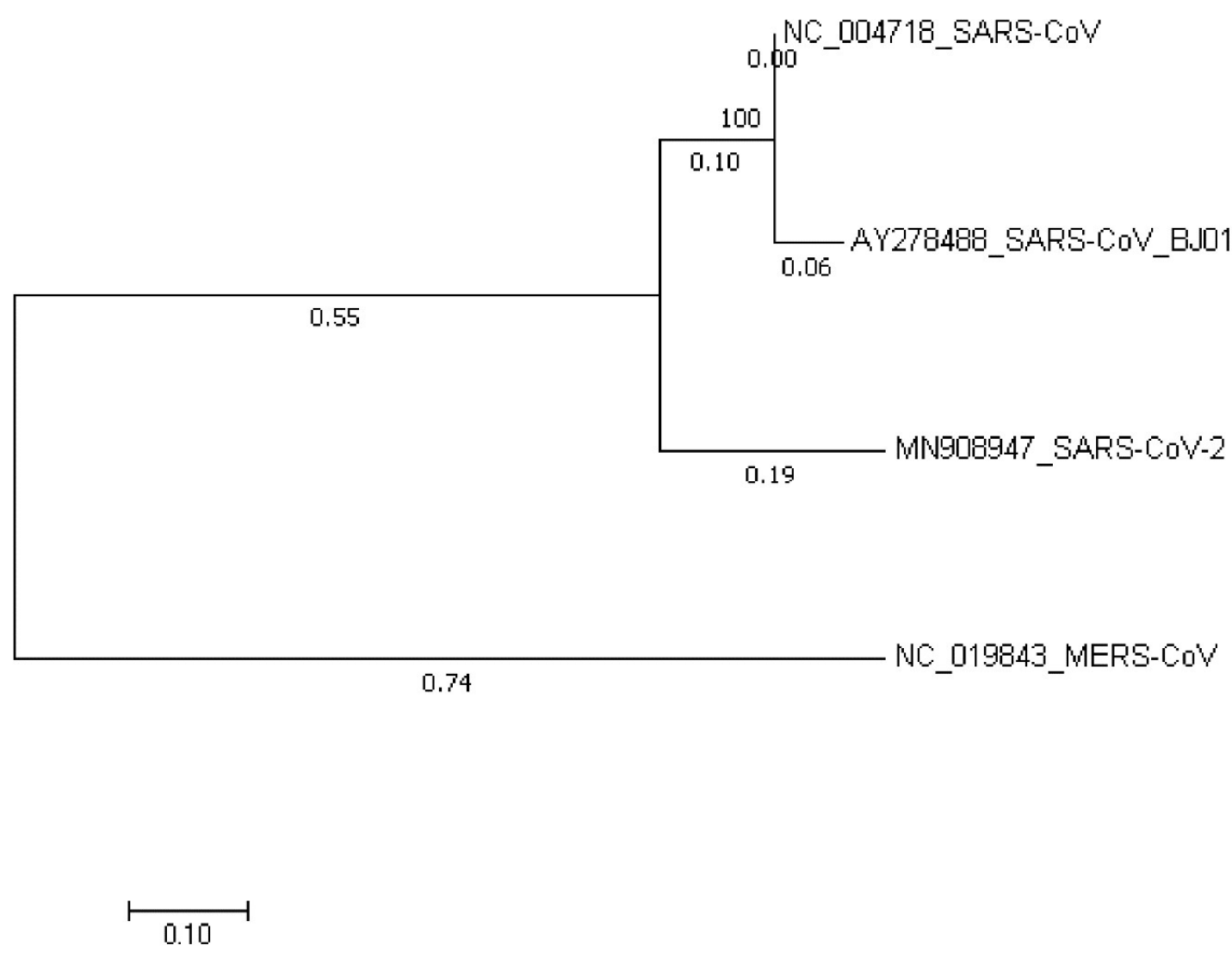

95 Phylogenetic analysis suggests that SARS-CoV and SARS-CoV-2 are closely related. The 96 close relation between SARS-CoV and SARS-CoV-2 is helpful to the inhibitor drugs 97 preparation, vaccine development, homology modelling and protein functions estimation.

\section{Genetic features}

99 The reported whole-genome sequence of SARS-CoV-2 has the size of 29903 nucleotides, from 100 which the number of adenine (A), guanine (G) are, thymine (T), cytosine (C) is 8954, 9594, 1015863,5492 nucleotides respectively as shown in figure 2. 
OSF Preprint

DOI: 10.31219/osf.io/9afp3

102

103

104

105 The whole-genome sequence is comprised of a 5' UTR (265 aa), 3' UTR (229 aa), 12 CDS, 16

106 Mature peptides and 5 Stem-Loops.

107 Table 1: Protein name, range, sequence length and NCBI reference for UTRs, CDS and Mature 108 peptides present in the whole genome sequence

\begin{tabular}{|c|c|c|c|c|}
\hline S.N. & Protein & $\begin{array}{l}\text { Gene range } \\
\left(5^{\prime}-3^{\prime}\right)\end{array}$ & $\begin{array}{l}\text { Sequence } \\
\text { length } \\
\text { (aa) }\end{array}$ & $\begin{array}{ll}\text { NCBI Reference } \\
\text { Sequence }\end{array}$ \\
\hline 1 & 5'UTR & $1-265$ & 265 & - \\
\hline 2 & ORF1AB polyprotein & $\begin{array}{l}266-13468, \\
13468- \\
21555\end{array}$ & 7096 & YP_009724389.1 \\
\hline 3 & Leader protein & $266-805$ & 180 & YP_009725297.1 \\
\hline 4 & NSP2 & $806-2719$ & 638 & YP_009725298.1 \\
\hline 5 & NSP3 & $2720-8554$ & 1945 & YP_009725299.1 \\
\hline 6 & NSP4 & $8555-10054$ & 500 & YP_009725300.1 \\
\hline 7 & 3CL-like protease & $\begin{array}{l}10055- \\
10972\end{array}$ & 306 & YP_009725301.1 \\
\hline 8 & NSP6 & $\begin{array}{l}10973- \\
11842\end{array}$ & 290 & YP_009725302.1 \\
\hline 9 & NSP7 & $\begin{array}{l}11843- \\
12091\end{array}$ & 83 & YP_009725303.1 \\
\hline 10 & NSP8 & $\begin{array}{l}12092- \\
12685\end{array}$ & 198 & YP_009725304.1 \\
\hline
\end{tabular}

Fig 2: Nucleotide frequencies in all 4 genome sequences

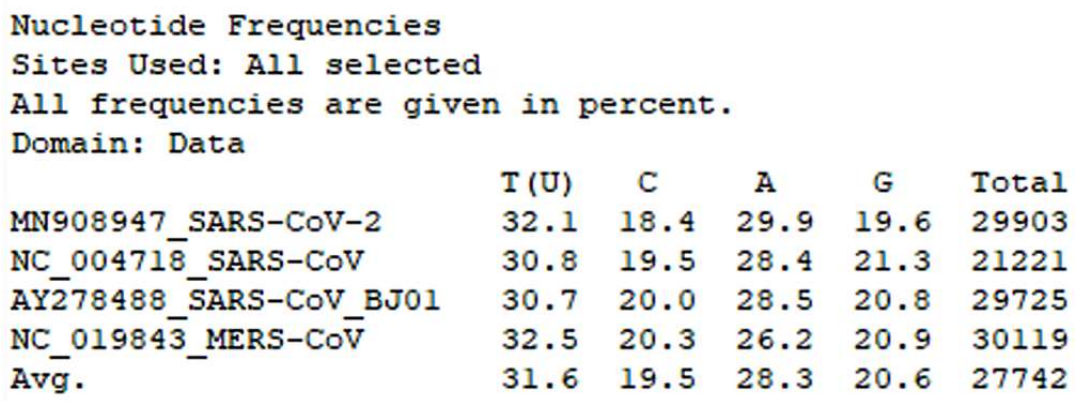


OSF Preprint

DOI: 10.31219/osf.io/9afp3

\begin{tabular}{|c|c|c|c|c|}
\hline 11 & NSP9 & $\begin{array}{l}12686- \\
13024\end{array}$ & 113 & YP_009725305.1 \\
\hline 12 & NSP10 & $\begin{array}{l}13025- \\
13441\end{array}$ & 139 & YP_009725306.1 \\
\hline 13 & NSP11 & $\begin{array}{l}13442- \\
13480\end{array}$ & 13 & YP_009725312.1 \\
\hline 14 & $\begin{array}{l}\text { RNA-dependent RNA } \\
\text { polymerase (NSP12) }\end{array}$ & $\begin{array}{l}13442- \\
16236\end{array}$ & 932 & YP_009725307.1 \\
\hline 15 & Helicase (NSP13) & $\begin{array}{l}16237- \\
18039\end{array}$ & 601 & YP_009725308.1 \\
\hline 16 & $\begin{array}{l}\text { 3'-to-5' exonuclease } \\
\text { (NSP14) }\end{array}$ & $\begin{array}{l}18040- \\
19620\end{array}$ & 527 & YP_009725309.1 \\
\hline 17 & endoRNAse (NSP15) & $\begin{array}{l}19621- \\
20658\end{array}$ & 346 & YP_009725310.1 \\
\hline 18 & $\begin{array}{l}\text { 2'-O-ribose methyltransferase } \\
\text { (NSP16) }\end{array}$ & $\begin{array}{l}20659- \\
21552\end{array}$ & 298 & YP_009725311.1 \\
\hline 19 & ORF1A polyprotein & $266-13483$ & 4405 & YP_009725295.1 \\
\hline 20 & Surface glycoprotein & $\begin{array}{l}21563- \\
25384\end{array}$ & 1237 & YP_009724390.1 \\
\hline 21 & ORF3a protein & $\begin{array}{l}25393- \\
26220\end{array}$ & 275 & YP_009724391.1 \\
\hline 22 & Envelope protein & $\begin{array}{l}26245- \\
26472\end{array}$ & 75 & YP_009724392.1 \\
\hline 23 & Membrane glycoprotein & $\begin{array}{l}26523- \\
27191\end{array}$ & 222 & YP_009724393.1 \\
\hline 24 & ORF6 protein & $\begin{array}{l}27202- \\
27387\end{array}$ & 61 & YP_009724394.1 \\
\hline 25 & ORF7a protein & $\begin{array}{l}27394- \\
27759\end{array}$ & 121 & YP_009724395.1 \\
\hline 26 & ORF7b & $\begin{array}{l}27756- \\
27887\end{array}$ & 43 & YP_009725318.1 \\
\hline 27 & ORF8 protein & $\begin{array}{l}27894- \\
28259\end{array}$ & 121 & YP_009724396.1 \\
\hline
\end{tabular}


OSF Preprint

DOI: 10.31219/osf.io/9afp3

\begin{tabular}{|l|l|l|l|l|}
\hline 28 & Nucleocapsid phosphoprotein & $\begin{array}{l}28274- \\
29533\end{array}$ & 419 & YP_009724397.2 \\
\hline 29 & ORF10 protein & $\begin{array}{l}29558- \\
29674\end{array}$ & 38 & YP_009725255.1 \\
& & $29675-$ & 229 & - \\
\hline 30 & 3' UTR & 29903 & & \\
\hline
\end{tabular}

109

\section{Protein structures and functions}

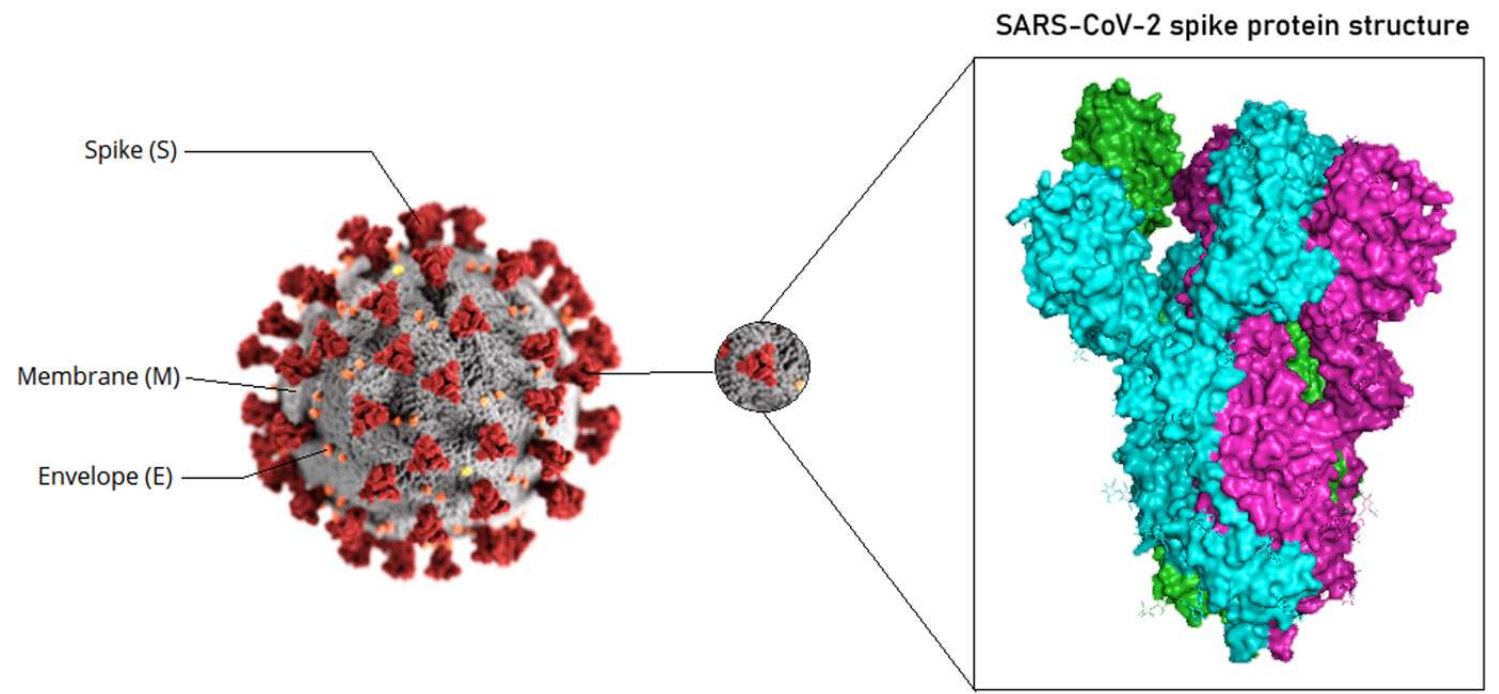

111

112

115

116

Fig 3: SARS-CoV-2 spike (S), membrane (M) and Envelop (E) proteins and enlarged structure of spike protein (PDB ID: 6VSB)

The individual protein structures are searched for existing models in RCSB PDB (http://www.rcsb.org/) database. When experimentally determined structures are not found for most of the proteins, then homology modelling approach is used to model protein structure.

SWISS-MODEL (https://swissmodel.expasy.org/) server is used to predict 3D homology models. UCSF Chimera (http://www.cgl.ucsf.edu/chimera) software is used to visualise the homology models. UniProtKB (https://www.uniprot.org/uniprot/), DrugBank (https://www.drugbank.ca/), NCBI (https://www.ncbi.nlm.nih.gov/) and available literature is used to compile the different function of the proteins. 


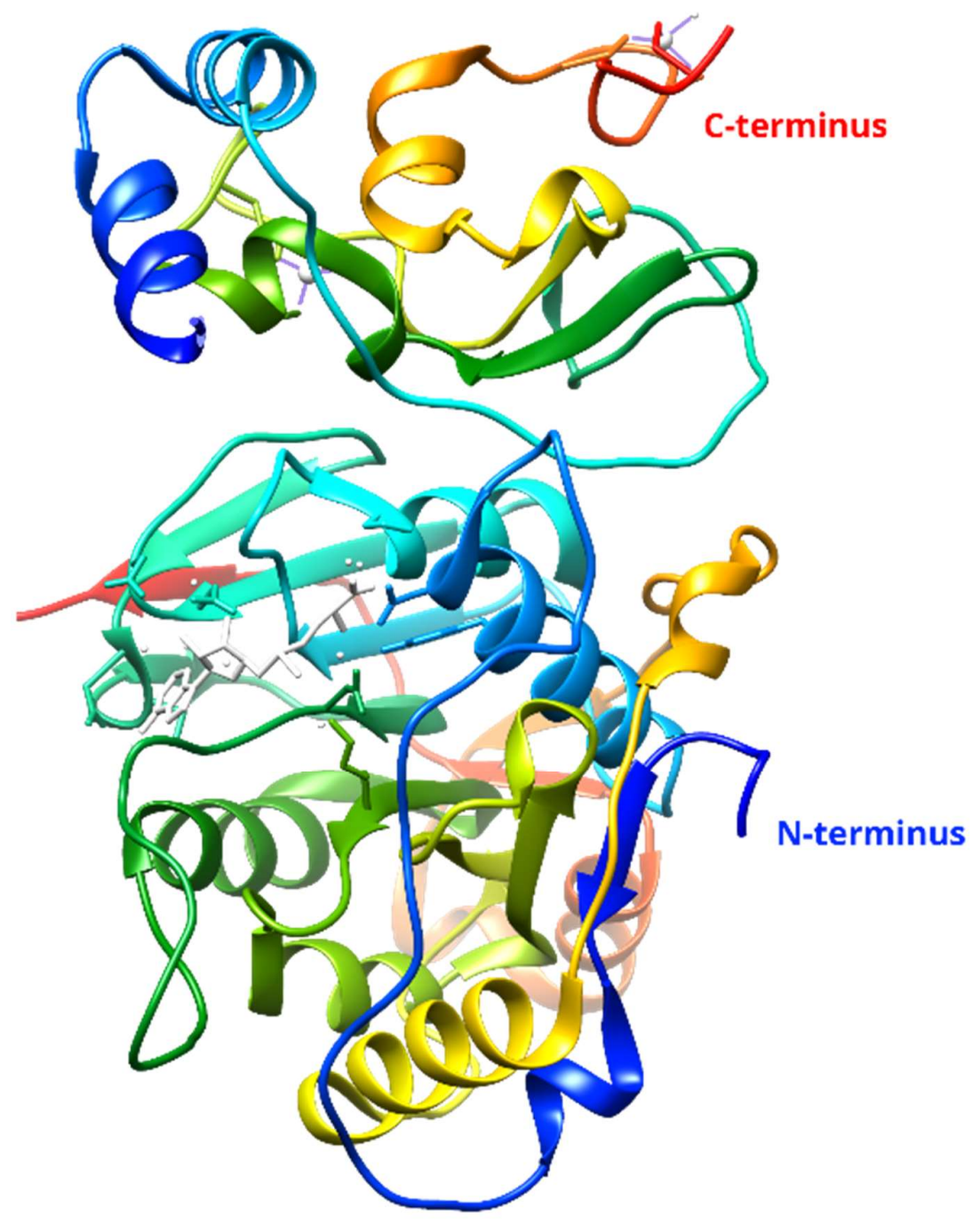

Fig 4: The 3D structure of ORF1AB polyprotein is available on PDB ID: $3 R 24$

Function: ORF1AB polyprotein has $95.55 \%$ identity with non-structural polyprotein $1 \mathrm{ab}$ [Bat SARS-like coronavirus] (Accession no. AVP78030.1).

Its general function is Zinc ion binding but it can also inhibit host translation by interacting with the $40 \mathrm{~S}$ ribosomal subunit.

ORF1ab proteins is a multifunctional protein involved in virus pathogenesis distinct from or in addition to functions directly involved in the transcription and replication of viral RNAs. Recent reverse genetic studies have confirmed that proteins of ORF1ab may be involved in cellular signalling and modification of cellular gene expression, as well as virulence by mechanisms yet to be determined (Graham et al., 2007). 


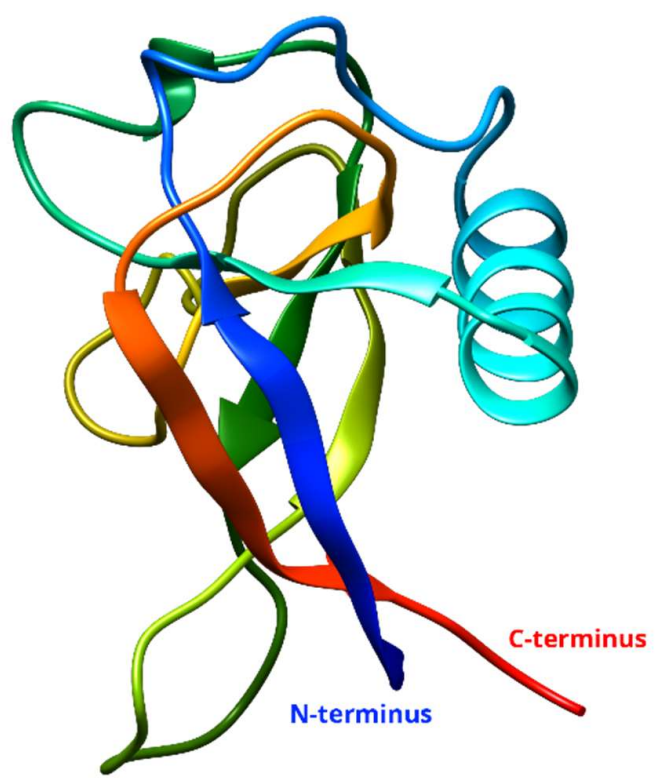

Fig 5: The 3D structure of the protein is modelled from the Swiss Model server. Template PDB ID: 2HSX was having a maximum sequence identity of $86.09 \%$

Function: SARS coronavirus NSP1 plays an important role in CCL5, CXCL10, and CCL3 expression in human lung epithelial cells via the activation of NF-kB (Law et al., 2006).

NSP2

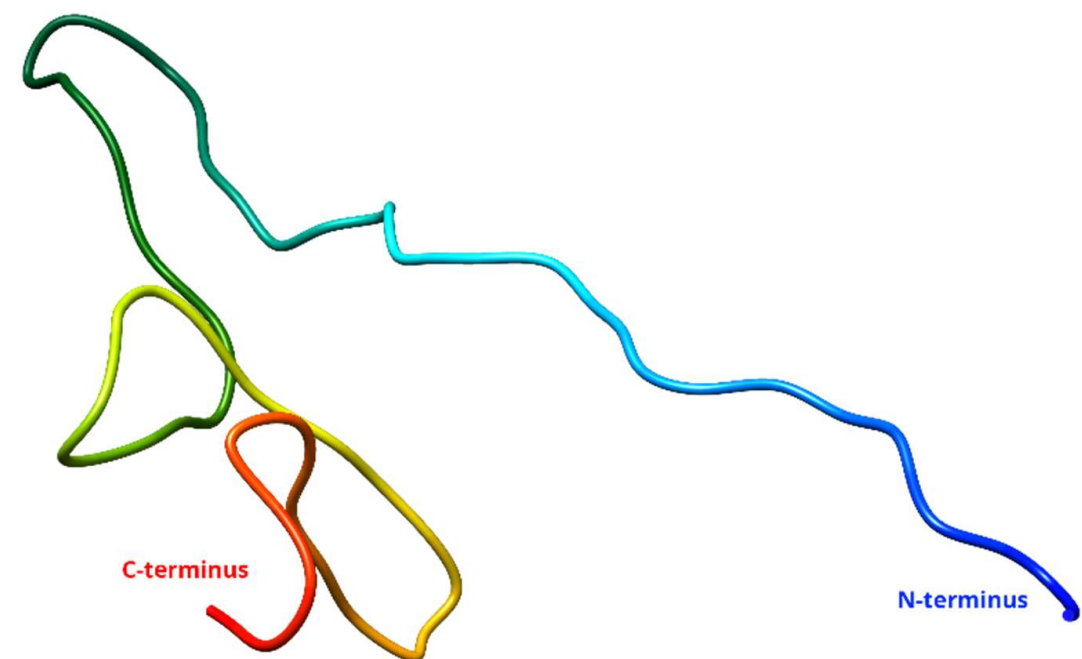

Fig 6: The 3D structure of the protein is modelled from the Swiss Model server. Template PDB ID: 4V7E was having a maximum sequence identity of $19.67 \%$

Function: NSP2 of SARS-CoV is dispensable for viral replication in the host cell. Deletion of the nsp2 coding sequence attenuates viral growth and RNA synthesis. (Graham et al., 2005). 
150

151

152

153

154

155

156

157

158

159

160

161

162

163

164

165

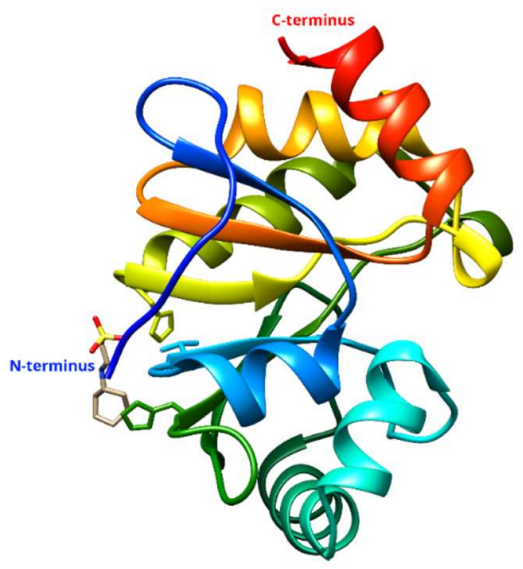

Fig 7: The 3D structure of the protein is modelled from the Swiss Model server. Template PDB ID: 6VXS was having a maximum sequence identity of $100 \%$

Function: NSP3 along with other NSPs is required for RNA transcription and genome replication as large polyprotein. These proteins are proteolytically processed by virus-encoded proteinases to produce mature replicase proteins (Prentice et al., 2004).

\section{NSP4}

Fig 8: The 3D structure of the protein is modelled from the Swiss Model server. Template PDB ID: $3 \mathrm{VCB}$ was having a maximum sequence identity of $61.36 \%$

Function: H120 \& F121 in the lumenal loop in NSP4 are essential for binding to NSP3. Interaction with NSP3 through H120 \& F121 in NSP4 is crucial for viral propagation. H120 \& F121 substitutions in NSP4 cause defect in membrane rearrangement function. Although, NSP3-NSP4 interaction is not sufficient to induce membrane rearrangement (Sakai et al., 2017). 
167

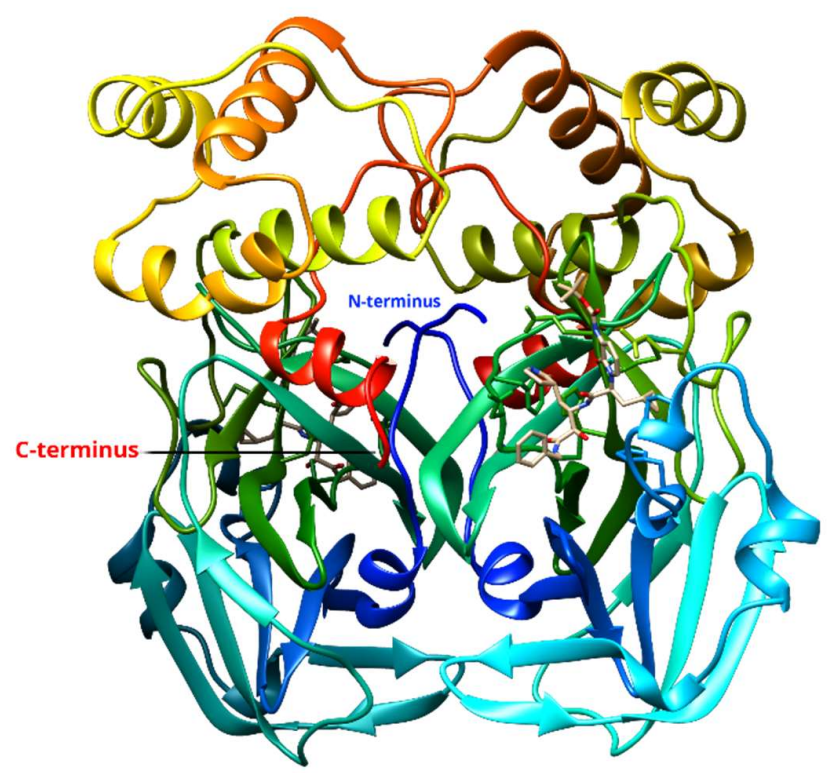

Fig 9: The 3D structure of the protein is modelled from the Swiss Model server. Template PDB ID: 6 Y2G was having a maximum sequence identity of $100 \%$

Function: NSP5 is essential for virus replication. Its activity is extensively regulated by intraand intermolecular interactions. NSP5 exhibits a conserved three-domain structure containing a chymotrypsin-like fold formed by domains 1 and 2 as well as the third domain of unclear function but which likely is important for the required dimerization of NSP5 (Stobart et al., 2013).

\section{NSP6}

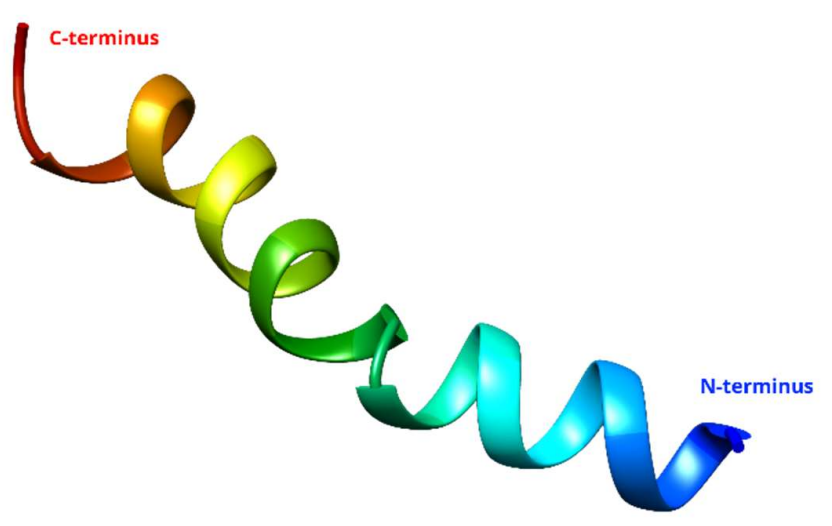

Fig 10: The 3D structure of the protein is modelled from the Swiss Model server. Template PDB ID: 5LC5 was having a maximum sequence identity of $18.52 \%$

Function: NSP6 has multiple transmembrane domain NSP6 of SARS-CoV is reported to induce the formation of DMVs in the transfected cells (Angelini et al., 2013). 
183

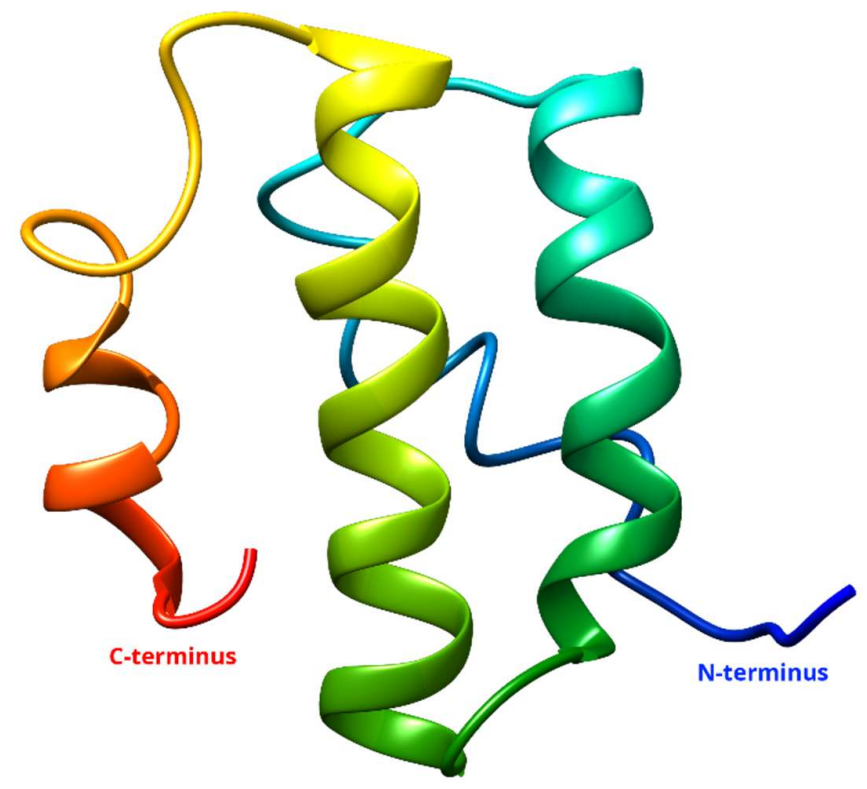

Fig 11: The 3D structure of the protein is modelled from the Swiss Model server. Template PDB ID: 1YSY was having a maximum sequence identity of $98.80 \%$

Function: NSP7 is an all-a-helical protein. The hexadecameric NSP7-NSP8 supercomplex implying that its role is to confer processivity on RNA-dependent RNA polymerase (Zhai et al., 2005).

\section{NSP8}

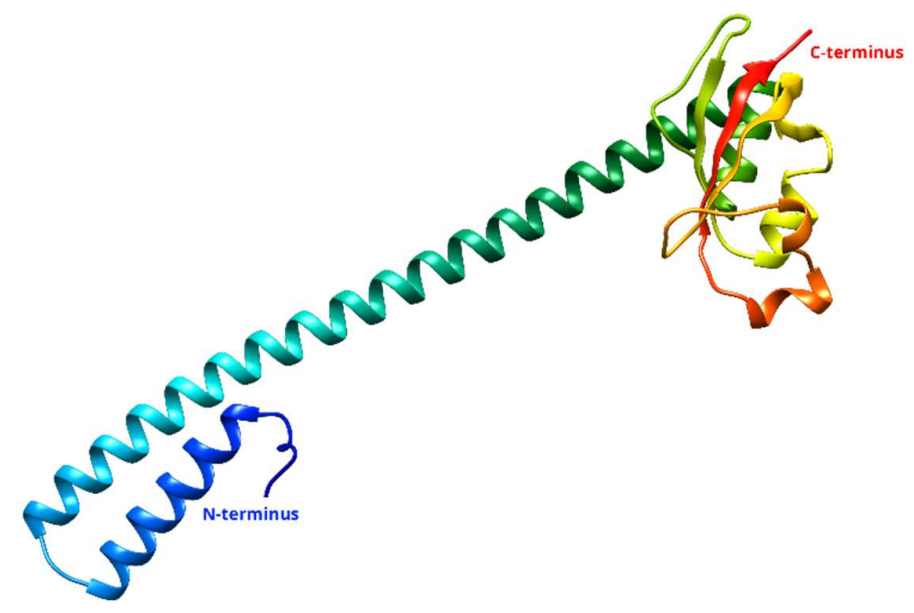

Fig 12: The 3D structure of the protein is modelled from the Swiss Model server. Template PDB ID: 2AHM was having a maximum sequence identity of $97.47 \%$

Function: NSP8 octamer makes NSP7+NSP8 complex with eight nsp7 molecules. This complex is reported as a unique multimeric RNA polymerase capable of both de novo initiation and primer extension. (Zhai et al., 2005), (te Velthuis et al., 2012), (Imbert et al., 2006). 
198

199

200

201

202

203

204

205

206

207

208

209

210

211

212

213

Fig 13: The 3D structure of the protein is modelled from the Swiss Model server. Template PDB ID: 1QZ8 was having a maximum sequence identity of $97.35 \%$

Function: NSP9 is a dimeric protein which has no designated function but is most likely involved with viral RNA synthesis. NSP9 binds to RNA and interacts with nsp8. (Sutton et al., 2004).

NSP10

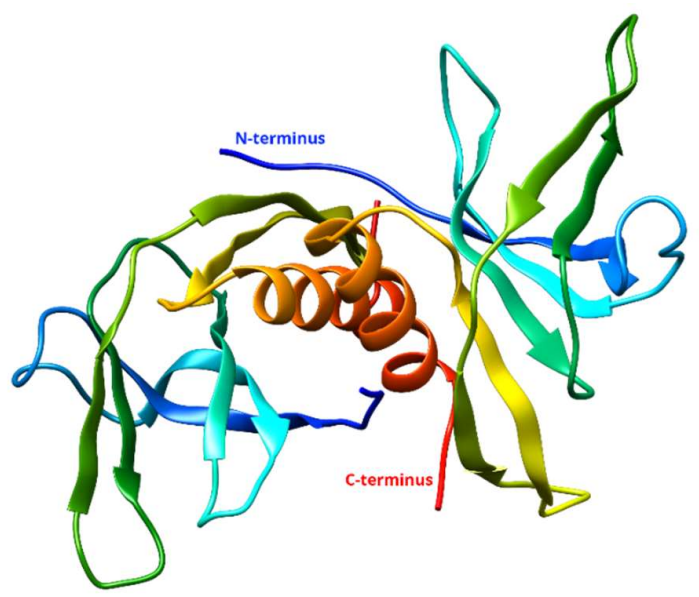
2004)

Fig 14: The 3D structure of the protein is modelled from the Swiss Model server. Template PDB ID: 5NFY was having a maximum sequence identity of $98.47 \%$

Function: Interaction between NSP10 and NSP14 or NSP16 has important implication for the mechanisms of replication/transcription complex assembly (Pan et al., 2008).

\section{NSP11}

NOTE: Protein sequence is very small, hence cannot be modelled

Function: Nsp15 play an important role in virus RNA synthesis (Wu et al., 2020). 


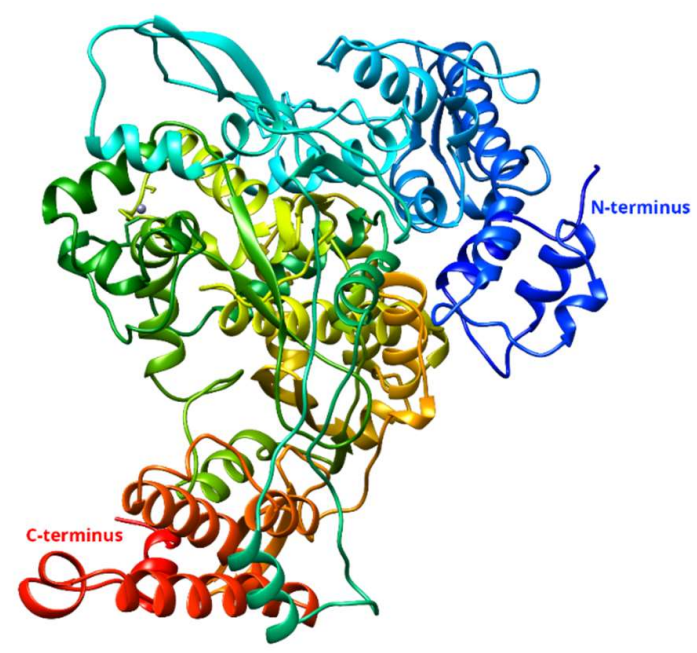

Fig 15: The 3D structure of the protein is modelled from the Swiss Model server. Template PDB ID: 6NUR was having a maximum sequence identity of $96.35 \%$

Function: RNA-dependent RNA polymerase (RdRp) in SARS-CoV showed both primer dependent and primer-independent RNA synthesis activities using homopolymeric RNA templates. It can initiate de novo RNA synthesis from the 3'-ends of both the plus- and minusstrand genome of SARS-CoV, using the 3'-terminal 36- and 37-nt RNA, respectively (Ahn et al., 2012), (Imbert et al., 2006).

\section{Helicase (NSP13)}

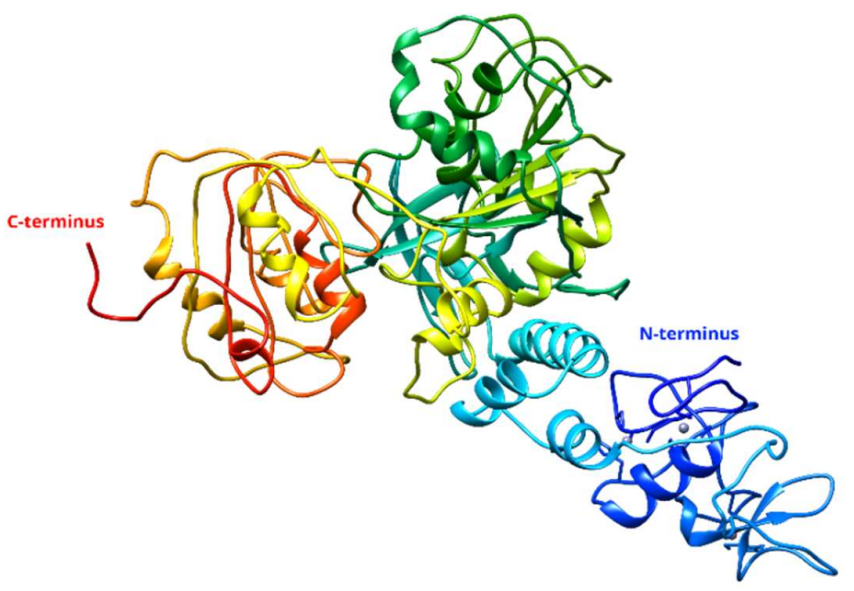

Fig 16: The 3D structure of the protein is modelled from the Swiss Model server. Template PDB ID: 6JYT was having a maximum sequence identity of $99.83 \%$

Function: Helicases are multifunctional proteins that are involved in diverse processes such as genome replication, subgenomic mRNA transcription, and 5' cap formation. RNA and DNA duplex-unwinding activities of NSP13 in SARS-CoV have also been reported (Ivanov et al., 2004). 


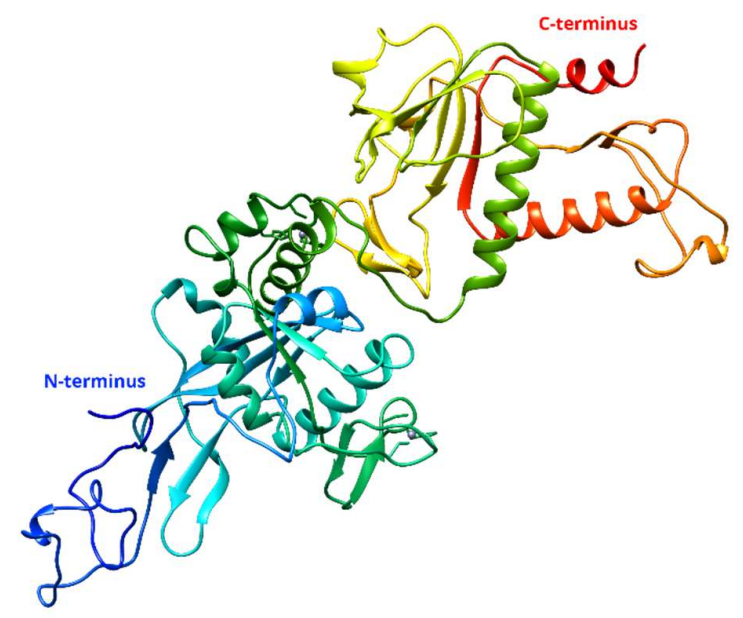

Fig 17: The 3D structure of the protein is modelled from the Swiss Model server. Template -

Function: 3'-to-5' exonuclease (ExoN) shows proofreading activity in SARS-CoV which may enhance the fidelity of RNA synthesis by correcting nucleotide incorporation errors made by the RNA-dependent RNA polymerase (Ogando et al., 2019).

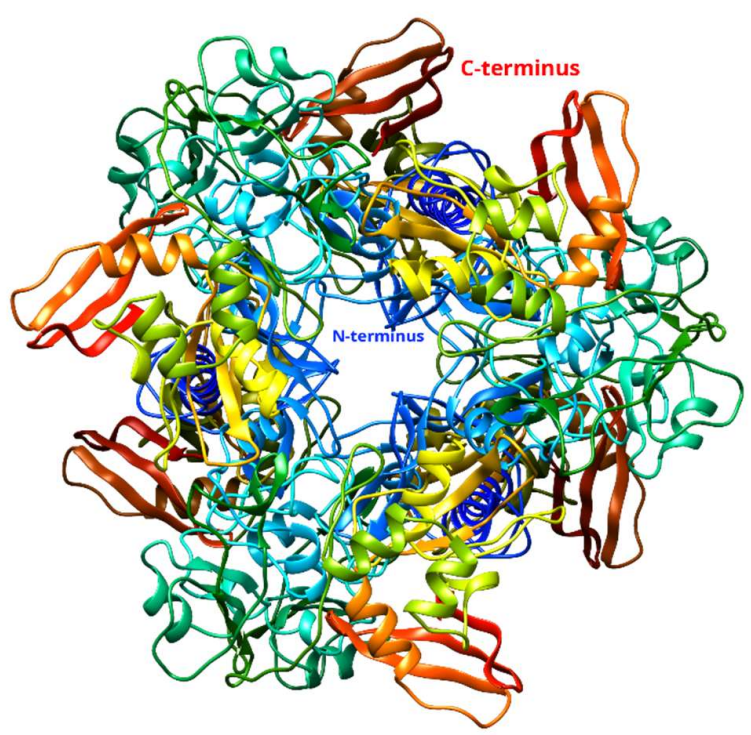

Fig 18: The 3D structure of the protein is modelled from the Swiss Model server. Template PDB ID: 6W01 was having a maximum sequence identity of $100 \%$

244 Function: Nsp15 has endoribonuclease activity and plays an important role in the virus RNA 245 synthesis (Wu et al., 2020). 
246 The endoribonucleolytic activity of NSP15 is reported for the orthologous protein from another 247 coronavirus, implying that the endoribonuclease activity of Nsp15 may be common to 248 coronaviruses (Bhardwaj et al., 2004).

251

252

253

254

255

256

257

258

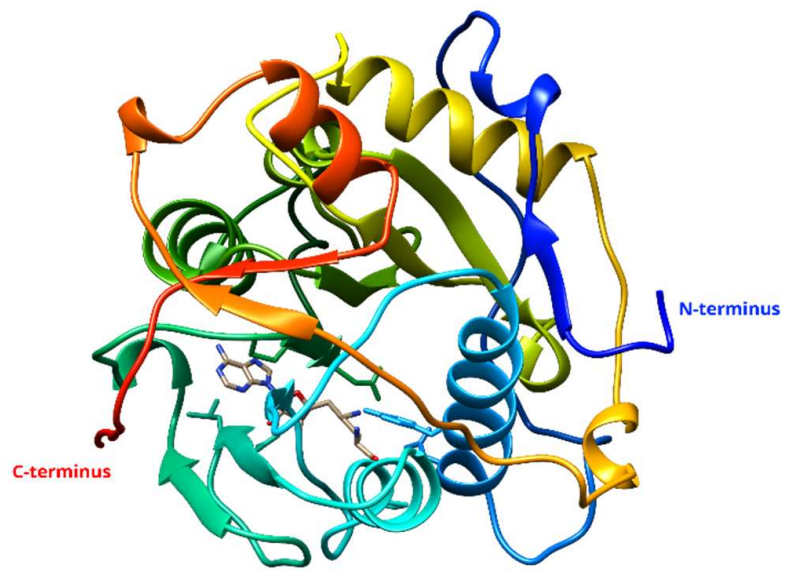

Fig 19: The 3D structure of the protein is modelled from the Swiss Model server. Template PDB ID: 2XYR was having a maximum sequence identity of $93.49 \%$

Function: Nsp16 in SARS-CoV requires NSP10 as a stimulatory factor to execute its MTase activity and the NSP16/NSP10 complex bound with methyl donor SAM. NSP16/NSP10 interface may represent a better drug target than the viral MTase (Chen et al., 2011).

\section{ORF1A polyprotein}

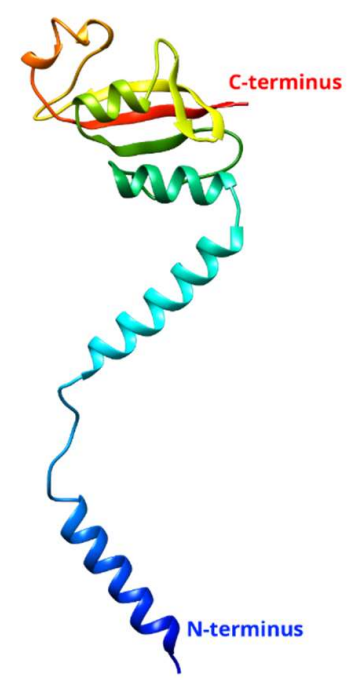

Fig 20: The 3D structure of the protein is modelled from the Swiss Model server. Template PDB ID: 2AHM was having a maximum sequence identity of $97.47 \%$

Function: Involved in the activation of host autophagy [ GO:0039520 ]. 
264

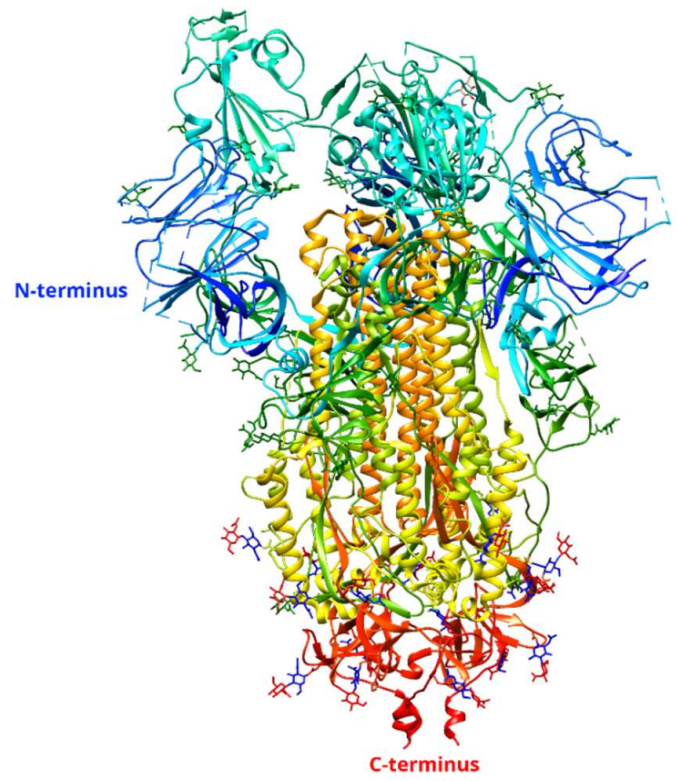

Fig 21: The 3D structure of surface glycoprotein is available on PDB ID: 6VSB

Function: Spike proteins which are present on the surface of virus shared a $76.5 \%$ identity and a high degree of homology with of SARS-CoV's spike protein structure (Xu et al., 2020).

The human ACE2 receptor (lysine 31) can recognize the SARS-CoV-2 receptor-binding domain (RBD) (glutamine 394) (Wan et al., 2020). The spike protein interaction with the ACE2 receptor and TMPRSS2 pave the way for the virus to enter into the host cell.

\section{ORF3a protein}

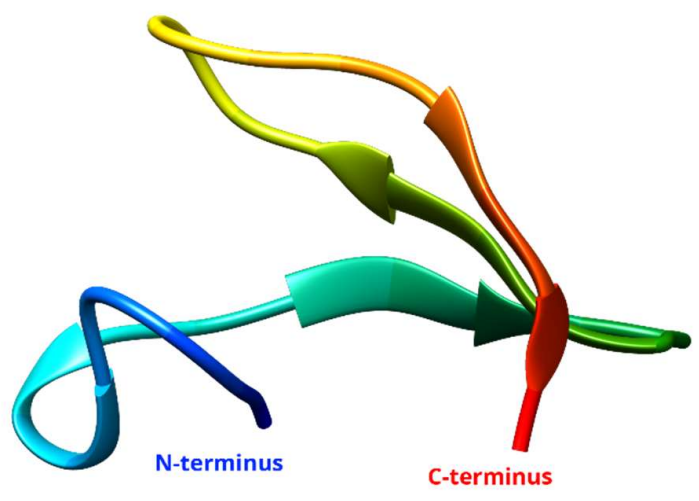

Fig 22: The 3D structure of the protein is modelled from the Swiss Model server. Template PDB ID: $2 \mathrm{M} 6 \mathrm{~N}$ was having a maximum sequence identity of $35.71 \%$

Function: ORF3a protein in SARS-CoV activates the NLRP3 inflammasome by promoting TNF receptor-associated factor 3 (TRAF3)-mediated ubiquitination of apoptosis-associated speck-like protein containing a caspase recruitment domain (ASC). It also activates pro-IL-1b gene expression and IL-1b secretion (Siu et al., 2020). 


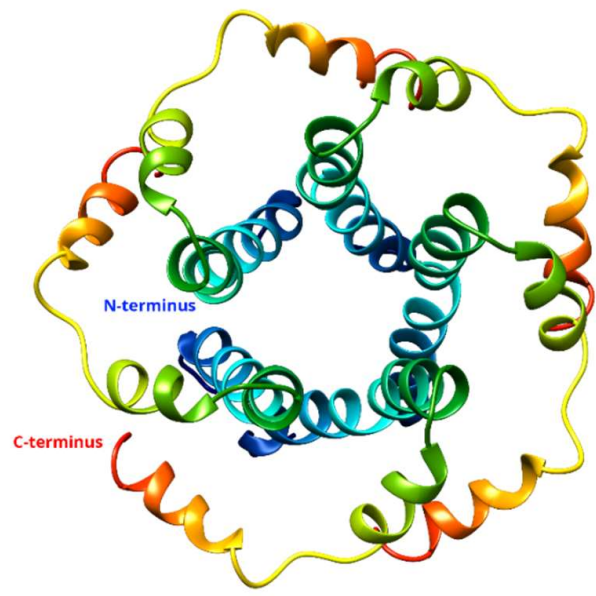

Fig 23: The 3D structure of the protein is modelled from the Swiss Model server. Template PDB ID: 5X29 was having a maximum sequence identity of $91.38 \%$

Function: E protein down-regulate the signalling pathway inositol-requiring enzyme 1 (IRE1) of the unfolded protein response, but not the PKR-like ER kinase (PERK). It activates the transcription factor 6 (ATF-6) pathways and also found to be involved in cell apoptosis. The protein also facilities the ion-conductive pore in the membrane (DeDiego et al., 2011).

\section{Membrane glycoprotein}

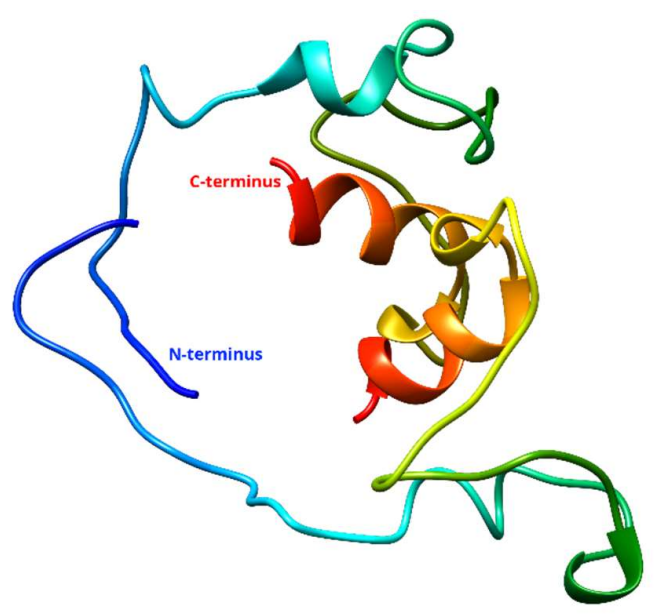

Fig 24: The 3D structure of the protein is modelled from the Swiss Model server. Template PDB ID: 6QPK was having a maximum sequence identity of $20 \%$

Function: Membrane glycoprotein of SARS-CoV can interact with nucleocapsid (N) protein in-vitro and in-vivo (He et al., 2004). M protein suppresses NF-kB activity through interaction with IKK $\beta$ which results in lower Cox-2 expression which contributes to SARS pathogenesis (Fang et al., 2007).

$\mathrm{M}$ protein has also reported containing highly conserved glycosylated sequences and its glycosylation helps to facilitate a viral-host interaction (de Haan et al.,1998). 
Fig 25: The 3D structure of the protein is modelled from the Swiss Model server. Template PDB ID: 5VYJ was having a maximum sequence identity of $25 \%$

Function: ORF6 protein can induce intracellular membrane rearrangements which results in a vesicular population in the infected cell.

It has been reported that a putative diacidic motif in the ORF6 protein influences its subcellular localization and ability to suppress the expression of co-transfected expression constructs (Gunalan et al., 2011).

\section{ORF7a protein}

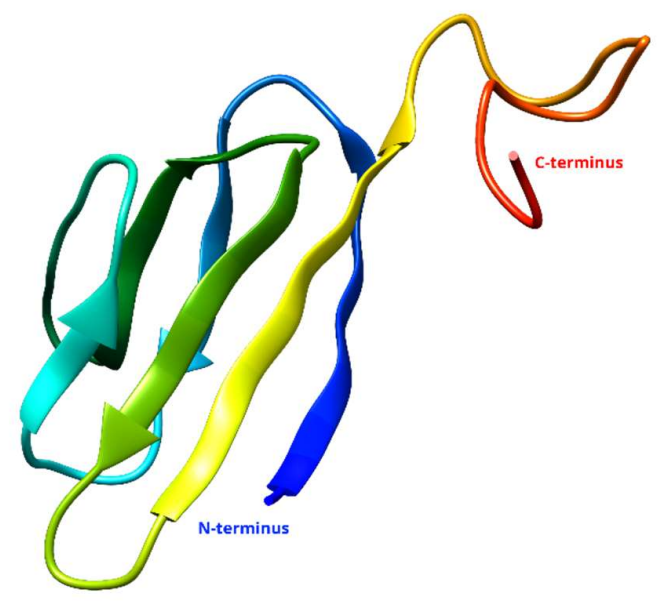

Fig 26: The 3D structure of the protein is modelled from the Swiss Model server. Template PDB ID: 1 YO4 was having a maximum sequence identity of $91.57 \%$

Function: ORF7a localize in the rER/Golgi apparatus and encodes a proapoptotic activity. Overexpression of ORF7a induces apoptosis via a caspase-dependent pathway (Tan et al., 2004). 
Fig 27: The 3D structure of the protein is modelled from the Swiss Model server. Template PDB ID: 5DOQ was having a maximum sequence identity of $30 \%$

Function: ORF7b protein is a structural component of SARS-CoV virions an integral membrane protein. It localizes to the Golgi apparatus and has its $\mathrm{C}$ terminus exposed to the cytoplasm (Schaecher et al., 2007).

Fig 28: The 3D structure of the protein is modelled from the Swiss Model server. Template PDB ID: 1XAK was having a maximum sequence identity of $21.57 \%$

328 Function: ORF8 protein sequence of SARS-CoV-2 ORF8 shared very low similarity with 329 sequences in SARS-CoV. It is functionally uncategorized. 


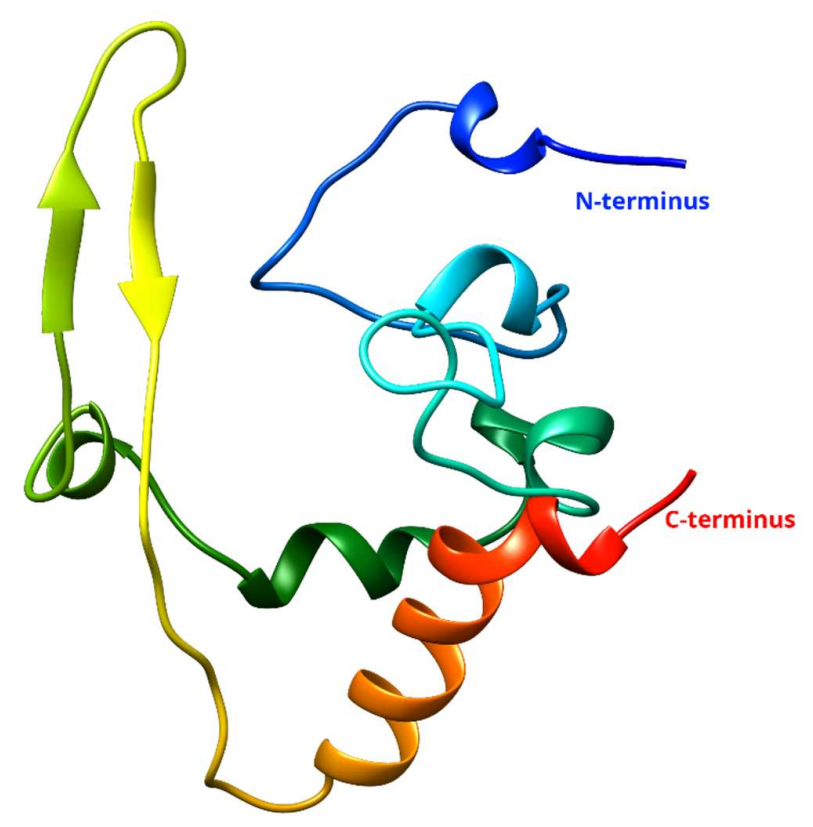

Fig 29: The 3D structure of the protein is modelled from the Swiss Model server. Template PDB ID: 2JW8 was having a maximum sequence identity of $95.76 \%$

Function: Nucleocapsid (N) phosphoprotein binds the viral RNA to form the helical core structure (Davies et al., 1981). Functions such as viral packaging, viral core formation, and signal transduction have been reported to the coronavirus nucleocapsid (Hiscoxet et al., 2001), (He et al., 2004).

\section{ORF10 protein}

NOTE: No matches were found for the target sequence for homology modelling

Function: ORF10 had a premature stop codon in both SARS-CoV. Its homology structure cannot be modelled due to no template matching.

\section{RESULTS AND DISCUSSION}

The whole-genome sequence of the novel coronavirus - SARS-CoV-2 is analysed. The local alignment was performed for the closely related 2 virus species (SARS-CoV and SARS-CoV2) by the Smith-Waterman algorithm. Bioinformatics software MEGA is used to perform MSA on closely related four virus species and then the phylogenic tree is prepared by the neighbourjoining method.

Homology modelling is performed and their structure identity noted for all the proteins whose PDB structures are not reported yet (as on March 16 2020). 


\section{OSF Preprint}

DOI: 10.31219/osf.io/9afp3

351 Functions for all the proteins are documented form the literature. As our local alignment results

352

353

354

355

356

357

358

359

360

361

362

363

364

365

366

367

368

369

370

371

372

373

374

375

376

377

378

379

380 show that SARS-CoV and SARS-CoV-2 have $79.8 \%$ similarity as well as the identity, hence most of the functions for proteins in SARS-CoV is been reported here because their exact function in SARS-CoV-2 is not known yet. Some protein functions of SARS-CoV-2 are recently in research focus such as spike protein, but further research is needed to reveal the role of all SARS-CoV-2 proteins and their mechanisms.

The predicted homologues proteins and their attenuated functions in this paper can be used as a preliminary step towards the exploration of exact protein functions in SARS-CoV-2. The homologues structures are prepared and sorted based on structural similarity with SARS-CoV proteins. This can ease the process of function detection in SARS-CoV-2 rather than a de novo approach.

Once the structure and the function of the protein are known, it will be easier to develop antiviral vaccines against COVID-19. Presently, spike proteins are under extreme research. It is reported that spike proteins interact with lysine 31 on the human ACE2 and TMPRSS2 on the host cell membrane. This interaction leads to the entry of SARS-CoV-2 inside the host cell.

Our analysis suggests that there may be other drug targets as well. NSPs such NSP10/NSP16 or NSP14 complex has importance in replication/transcription assembly. NSPs can be targeted to halt the viral transcription inside the host cell of a sever infected person.

Similarly, membrane protein and nucleocapsid protein may be targeted to limit the virus-host interaction. ORF proteins are not much explored in SARS-CoV-2. ORF10 does not match any template and hence is not modelled. Its function is also very less explored.

Researchers around the world are using a new technique for fast vaccine development known as Rapid Response Platform. Rather than sending the antigens in the body, as traditional method, RRP vaccines send RNA/DNA directly into the cells in order to manufacture response antigen inside the host cell. This method of vaccine development is less time consuming and more specific as compared to the traditional method.

Other advantage to this technique is that when the RNA/DNA used to make antigens against one type of virus is developed, it can easily be manipulated to make antigens against other strads of viruses. Knowing the whole-genome sequence and the function each protein performs may add up to the RRP vaccine development process. 
381 Exploring the structural and functional characteristics of SARS-CoV-2 whole genome may enable us to create recombinant SARS-CoV-2 vectors with desired and limited capabilities. The protein machinery of recombinant SARS-CoV-2 even can be used to deliver anti-viral drug or RNA to create specific antibodies. We present a complied record as a preliminary step to understand the lesser-explored proteins of SARS-CoV-2 and contribute to the process of anti-viral drug development.

\section{Acknowledgments:}

Research in D.D.S. lab is supported by Indian Council of Medical Research, New Delhi, India110029, Biotechnology Industry Research Assistance Council, New Delhi, India, FIST-DST, India and John Templeton Foundation USA. Author's extend his appreciation towards COVID19 Researcher's Globally.

CONFLICT OF INTEREST: The authors declare no conflict of interest, financial or otherwise.

\section{REFERENCES}

1. Gralinski LE, Menachery VD. Return of the coronavirus: 2019-nCoV. Viruses. 2020;12(2):1-8. doi:10.3390/v12020135

2. Zhou P, Yang X-L, Wang X-G, et al. A pneumonia outbreak associated with a new coronavirus of probable bat origin. Nature. 2020;579(March). doi:10.1038/s41586-020-2012-7

3. $\mathrm{Xu} X$, Chen $\mathrm{P}$, Wang J, et al. Evolution of the novel coronavirus from the ongoing Wuhan outbreak and modeling of its spike protein for risk of human transmission. Science China Life Sciences. 2020;63(3):457-460. doi:10.1007/s11427-020-1637-5

4. Li F, Li W, Farzan M, Harrison SC. Structural biology: Structure of SARS coronavirus spike receptor-binding domain complexed with receptor. Science. 2005;309(5742):1864-1868. doi:10.1126/science.1116480

5. Pettersen EF, Goddard TD, Huang CC, et al. UCSF Chimera--a visualization system for exploratory research and analysis. Journal of computational chemistry. 2004;25(13):1605-1612. doi:10.1002/jcc.20084

6. Graham RL, Sparks JS, Eckerle LD, Sims AC, Denison MR. SARS coronavirus replicase proteins in pathogenesis. Virus research. 2008;133(1):88100. doi:10.1016/j.virusres.2007.02.017

7. Law AHY, Lee DCW, Cheung BKW, Yim HCH, Lau ASY. Role for Nonstructural Protein 1 of Severe Acute Respiratory Syndrome Coronavirus in 
OSF Preprint

DOI: 10.31219/osf.io/9afp3

Chemokine Dysregulation. Journal of Virology. 2007;81(1):416-422. doi: $10.1128 /$ jvi.02336-05

8. Graham RL, Sims AC, Baric RS, Denison MR. The nsp2 proteins of mouse hepatitis virus and SARS coronavirus are dispensable for viral replication. Advances in Experimental Medicine and Biology. 2005;581(21):67-72. doi:10.1007/978-0-387-33012-9_10

9. Prentice E, McAuliffe J, Lu X, Subbarao K, Denison MR. Identification and Characterization of Severe Acute Respiratory Syndrome Coronavirus Replicase Proteins. Journal of Virology. 2004;78(18):9977 LP - 9986. doi:10.1128/JVI.78.18.9977-9986.2004

10. Sakai Y, Kawachi K, Terada Y, Omori H, Matsuura Y, Kamitani W. Twoamino acids change in the nsp4 of SARS coronavirus abolishes viral replication. Virology. 2017;510(June):165-174. doi:10.1016/j.virol.2017.07.019

11. Stobart CC, Sexton NR, Munjal H, et al. Chimeric Exchange of Coronavirus nsp5 Proteases (3CLpro) Identifies Common and Divergent Regulatory Determinants of Protease Activity. Journal of Virology. 2013;87(23):1261112618. doi:10.1128/jvi.02050-13

12. Angelini MM, Akhlaghpour M, Neuman BW, Buchmeier MJ. Severe Acute Respiratory Syndrome Coronavirus Nonstructural Proteins 3, 4, and 6 Induce Double-Membrane Vesicles. Moscona A, ed. mBio. 2013;4(4):e00524-13. doi:10.1128/mBio.00524-13

13. Zhai Y, Sun F, Li X, et al. Insights into SARS-CoV transcription and replication from the structure of the nsp7-nsp8 hexadecamer. Nature Structural and Molecular Biology. 2005;12(11):980-986. doi:10.1038/nsmb999

14. te Velthuis AJW, van den Worm SHE, Snijder EJ. The SARS-coronavirus nsp7+nsp8 complex is a unique multimeric RNA polymerase capable of both de novo initiation and primer extension . Nucleic Acids Research. 2011;40(4):1737-1747. doi:10.1093/nar/gkr893

15. Imbert I, Guillemot JC, Bourhis JM, et al. A second, non-canonical RNAdependent RNA polymerase in SARS coronavirus. EMBO Journal. 2006;25(20):4933-4942. doi:10.1038/sj.emboj. 7601368

16. Sutton G, Fry E, Carter L, et al. The nsp9 Replicase Protein of SARSCoronavirus, Structure and Functional Insights. Structure. 2004;12(2):341-353. doi:10.1016/j.str.2004.01.016

17. Pan J, Peng X, Gao Y, et al. Genome-wide analysis of protein-protein interactions and involvement of viral proteins in SARS-CoV replication. PLoS ONE. 2008;3(10). doi:10.1371/journal.pone.0003299

18. Wu C, Liu Y, Yang Y, et al. Analysis of therapeutic targets for SARS-CoV-2 and discovery of potential drugs by computational methods. Acta Pharmaceutica Sinica B. 2020;(PG-). doi:https://doi.org/10.1016/j.apsb.2020.02.008 
19. Ahn DG, Choi JK, Taylor DR, Oh JW. Biochemical characterization of a recombinant SARS coronavirus nsp12 RNA-dependent RNA polymerase capable of copying viral RNA templates. Archives of Virology. 2012;157(11):2095-2104. doi:10.1007/s00705-012-1404-x

20. Ivanov KA, Thiel V, Dobbe JC, van der Meer Y, Snijder EJ, Ziebuhr J. Multiple Enzymatic Activities Associated with Severe Acute Respiratory Syndrome Coronavirus Helicase. Journal of Virology. 2004;78(11):5619-5632. doi:10.1128/jvi.78.11.5619-5632.2004

21. Ogando NS, Ferron F, Decroly E, Canard B, Posthuma CC, Snijder EJ. The Curious Case of the Nidovirus Exoribonuclease: Its Role in RNA Synthesis and Replication Fidelity. Frontiers in Microbiology. 2019;10(August):1-17. doi:10.3389/fmicb.2019.01813

22. Bhardwaj K, Guarino L, Kao CC. The Severe Acute Respiratory Syndrome Coronavirus Nsp15 Protein Is an Endoribonuclease That Prefers Manganese as a Cofactor. Journal of Virology. 2004;78(22):12218 LP - 12224. doi:10.1128/JVI.78.22.12218-12224.2004

23. Chen $\mathrm{Y}, \mathrm{Su} \mathrm{C}, \mathrm{Ke} \mathrm{M}$, et al. Biochemical and structural insights into the mechanisms of sars coronavirus RNA ribose 2'-O-methylation by nsp16/nsp10 protein complex. PLoS Pathogens. 2011;7(10). doi:10.1371/journal.ppat.1002294

24. Wan Y, Shang J, Graham R, Baric RS, Li F. Receptor recognition by novel coronavirus from Wuhan: An analysis based on decade-long structural studies of SARS. Journal of Virology. 2020;(January). doi:10.1128/jvi.00127-20

25. Siu KL, Yuen KS, Castaño-Rodriguez C, et al. Severe acute respiratory syndrome coronavirus ORF3a protein activates the NLRP3 inflammasome by promoting TRAF3-dependent ubiquitination of ASC. FASEB journal : official publication of the Federation of American Societies for Experimental Biology. 2019;33(8):8865-8877. doi:10.1096/fj.201802418R

26. DeDiego ML, Nieto-Torres JL, Jiménez-Guardeño JM, et al. Severe acute respiratory syndrome coronavirus envelope protein regulates cell stress response and apoptosis. PLoS Pathogens. 2011;7(10). doi:10.1371/journal.ppat.1002315

27. He R, Leeson A, Ballantine M, et al. Characterization of protein-protein interactions between the nucleocapsid protein and membrane protein of the SARS coronavirus. Virus Research. 2004;105(2):121-125. doi:10.1016/j.virusres.2004.05.002

28. Fang X, Gao J, Zheng H, et al. The membrane protein of SARS-CoV suppresses NF- $\kappa$ B activation. Journal of Medical Virology. 2007;79(10):14311439. doi:10.1002/jmv.20953

29. de Haan CAM, Kuo L, Masters PS, Vennema H, Rottier PJM. Coronavirus Particle Assembly: Primary Structure Requirements of the Membrane Protein. 
Journal of Virology. 1998;72(8):6838-6850. doi:10.1128/jvi.72.8.68386850.1998

30. Gunalan V, Mirazimi A, Tan YJ. A putative diacidic motif in the SARS-CoV ORF6 protein influences its subcellular localization and suppression of expression of co-transfected expression constructs. BMC Research Notes. 2011;4:1-9. doi:10.1186/1756-0500-4-446

31. Tan Y-J, Fielding BC, Goh P-Y, et al. Overexpression of 7a, a Protein Specifically Encoded by the Severe Acute Respiratory Syndrome Coronavirus, Induces Apoptosis via a Caspase-Dependent Pathway. Journal of Virology. 2004;78(24):14043-14047. doi:10.1128/jvi.78.24.14043-14047.2004

32. Schaecher SR, Mackenzie JM, Pekosz A. The ORF7b Protein of Severe Acute Respiratory Syndrome Coronavirus (SARS-CoV) Is Expressed in VirusInfected Cells and Incorporated into SARS-CoV Particles. Journal of Virology. 2007;81(2):718-731. doi:10.1128/jvi.01691-06

33. Davies HA, Dourmashkin RR, Macnaughton MR. Ribonucleoprotein of Avian Infectious Bronchitis Virus. Journal of General Virology. 1981;53(1):67-74. doi:10.1099/0022-1317-53-1-67

34. Hiscox JA, Wurm T, Wilson L, Britton P, Cavanagh D, Brooks G. The Coronavirus Infectious Bronchitis Virus Nucleoprotein Localizes to the Nucleolus. Journal of Virology. 2001;75(1):506 LP - 512. doi:10.1128/JVI.75.1.506-512.2001 